\title{
Ophiopogonin B sensitizes TRAIL-induced apoptosis through activation of autophagy flux and downregulates cellular FLICE- like inhibitory protein
}

\author{
Uddin MD. Nazim ${ }^{1, *}$, Jae-Kyo Jeong ${ }^{1, *}$ and Sang-Youel Park ${ }^{1}$ \\ ${ }^{1}$ Biosafety Research Institute, College of Veterinary Medicine, Chonbuk National University, Iksan, Jeonbuk 54596, South \\ Korea \\ "These authors are equal contribution to this work
}

Correspondence to: Sang-Youel Park, email: sypark@chonbuk.ac.kr

Keywords: ophiopogonin; autophagy; TRAIL; apoptosis; lung cancer cells

Received: September 19, $2017 \quad$ Accepted: December 15, $2017 \quad$ Published: December 23, 2017

Copyright: Nazim et al. This is an open-access article distributed under the terms of the Creative Commons Attribution License 3.0 (CC BY 3.0), which permits unrestricted use, distribution, and reproduction in any medium, provided the original author and source are credited.

\section{ABSTRACT}

Tumor necrosis factor related apoptosis-inducing ligand (TRAIL), a type II transmembrane protein, belongs to the TNF superfamily. Compared to other family members, TRAIL is a promising anti-cancer agent that can selectively induce apoptosis of various types of transformed cells and xenografts, with negligible cytotoxicity against normal tissues. Ophiopogonin B is a bioactive ingredient of Radix Ophiopogon japonicus, which is frequently used in traditional Chinese medicine to treat cancer. In this study, we report that Cellular FLICE (FADD-like IL-1 $\beta$-converting enzyme)inhibitory protein (C-FLIP) is the key determinant mediating TRAIL resistance in A549 cells and Ophiopogonin B downregulates c-FLIP and enhances TRAIL-induced apoptosis by activating autophagy flux. In addition, treatment with Ophiopogonin $B$ resulted in a slight increase in the conversion of LC3-I to LC3-II and significantly decreased p62 expression levels in a dose-dependent manner. This indicates that Ophiopogonin B induces autophagy flux activation in human lung cancer cells. Inhibiting autophagy flux by applying a specific inhibitor ATG5 siRNA with Ophiopogonin B mediated enhancement of TRAIL effects. These data demonstrate that downregulation of C-FLIP by Ophiopogonin B enhances TRAIL-induced tumor cell death by activating autophagy flux in TRAIL-resistant A549 cells, and also suggests that Ophiopogonin B combined with TRAIL may be a successful therapeutic strategy for TRAIL-resistant lung cancer cells.

\section{INTRODUCTION}

Lung carcinoma is one of the principal reasons of cancer-related death worldwide [1]. After diagnosis, only $17.4 \%$ of all lung carcinoma patients live longer than 5 years [2]. In 2012, over 1.8 million people throughout the world had lung cancer, which is estimated to have caused 1.6 million deaths worldwide [3]. Chemotherapy and radiotherapy are the main tools for cancer therapy after surgery. Commencing cancers are infrequently resistant to single method. For this group of patients, combination chemotherapy can extend the 5-year survival rate and prevent recurrence.
Tumor necrosis factor related apoptosis-inducing ligand (TRAIL), also conversant as Apo-2 ligand and TNFSF10, is a type II transmembrane protein that associates to the TNF superfamily $[4,5]$. TRAIL is a promising anti-cancer agent that can selectively initiate cell death in various patterns of transformed cells and xenografts, with negligible cytotoxicity against normal tissues [4-6]. TRAIL exerts its pro-apoptotic effect on tumor cells through interaction with membrane receptors, including death receptors. On the contrary, the binding of TRAIL to decoy receptors or osteoprotegerin perpetrates the opposite effect [7]. The interrelation of TRAIL and death receptors recruits Fas-associated protein with death 
domain and initiator caspase-8, leading to the composition of death-inducing signaling complex [8-10]. In DISC, pro-caspase-8/10 is auto-cleaved to create an active form. This pathway is deactivated by the c-FLIP, which encloses the processing and stimulation of caspase- 8 at the level of DISC formation [11]. To date, three c-FLIP isoforms -c-FLIP-long (c-FLIPL), c-FLIP-short (c-FLIPS), and c-FLIPR - have been recognized at the protein level [1214], and elevated expression of both c-FLIPL and c-FLIPS isoforms were reported in some lung cancers [15].

Ophiopogonin B (OP-B) is a bioactive ingredient of Radix Ophiopogon japonicas, which is an evergreen long-lived medicinal herb. It has been used extensively in Southeast Asia to treat pulmonary disease for many years [16]. Ophiopogon japonicas contains the following active components: saponins, polysaccharides, and homoisoflavonoids [17]. Ophiopogonin B, which is partitioned from the traditional Chinese medicinal herb Radix $O$. japonicus, has been determined to exert anticancer effects in cervical cancer and human NSCLC $[16,18]$.

Autophagy is a lysosome-negotiated multi-step degradation scheme that appears in total eukaryotic cells from yeast to mammals [19]. Assembly of ULK1/2ATG13-FIP200 complex, which causes elevated levels of an isolation membrane named the phagophore, initiates autophagy. The phagophore extends to engulf a variety of intracellular cargo, including Golgi, mitochondria and damaged organelles to form a vesicle named autophagosome. The development of the autophagosome is indefinite on the class III PI3K compound and recruits autophagy-connected genes to enable the elongation and repletion of the autophagosome [20, 21]. The autophagosome solves with an autolysosome where the cargo is degraded and recycled to the cytosol for the defense of basic metabolism [19, 22, 23]. Although the role of autophagy in tumors is complicated and dependent on various aspects such as tumor type, stage, and genetic affection, it definitely plays an important role in cancer biology [24].

Although the anti-cancer benefit of Ophiopogonin B is well known, its synergy with TRAIL and the molecular outcomes involved are recently unclear. Consequently, the destination of this plan was to ascertain benefit of Ophiopogonin B and its synergistic result in combination with TRAIL.

\section{RESULTS}

\section{Ophiopogonin B sensitizes TRAIL-initiated apoptosis in A549 cells}

We visualized A549 cells using a microscope to supervise the morphological alteration. TRAIL or Ophiopogonin B alone marginally commenced cell death
(Figure 1) and no morphological novelty was established. Notwithstanding, combined regimen of TRAIL with different doses of Ophiopogonin B attenuated cell viability compared with Ophiopogonin B or TRAIL (Figure 1A1D). These data suggest that Ophiopogonin B sensitizes lung adenocarcinoma A549 cells to TRAIL-arbitrated apoptosis.

\section{Ophiopogonin B induces autophagy and sensitizes cells to apoptosis arbitrated by TRAIL}

As demonstrated in Figure 2A, expression of DR4 and DR5 were unaltered by Ophiopogonin B at any concentration. Nevertheless, LC3-II level was increased and that of p62 attenuated after Ophiopogonin $\mathrm{B}$ treatment (Figure 2B). Immunofluorescent staining results also indicated that increasing concentrations of Ophiopogonin B attenuated p62 levels (Figure 2C). A transmission electron microscopy result confirmed that sufficient autophagic and empty vacuoles exposed with Ophiopogonin B treatment (Figure 2D). Combined regimen with Ophiopogonin B and TRAIL sensitized expression of Ac-cas3 and Ac-cas8 (Figure 2E). These findings revealed that Ophiopogonin B could incite autophagy.

\section{Ophiopogonin B-mediated enhancement of TRAIL-initiated apoptosis is enclosed by attenuation of autophagy}

As demonstrated in, co-treatment of chloroquine, Ophiopogonin B and TRAIL enclosed cell death. Morphological consequences confirmed that chloroquine enclosed the cell death outcome (Figure 3A). Co-treatment of chloroquine, TRAIL and Ophiopogonin B significantly sensitized viability with strongly attenuated cell death (Figure 3B-3D). These findings revealed that chloroquine could block Ophiopogonin B-arbitrated apoptosis initiated by TRAIL.

\section{Attenuation of autophagy encloses TRAIL- arbitrated apoptosis sensitized by Ophiopogonin $B$ via incitation of autophagy flux}

The expression of DR4 and DR5 were unaltered by chloroquine or Ophiopogonin B alone, or by combined regimen (Figure 4A). Autophagy adoption was more characterized by the inspection of autophagy flux applying chloroquine. Chloroquine evolved accumulation of LC3-II and a decrease in p62 levels (Figure 4B). Immunofluorescent staining findings also approved that Ophiopogonin B attenuated the p62 protein (Figure 4C). The combined regimen with Ophiopogonin B and TRAIL sensitized the expression of Ac-cas3 and Ac-cas8. 
A

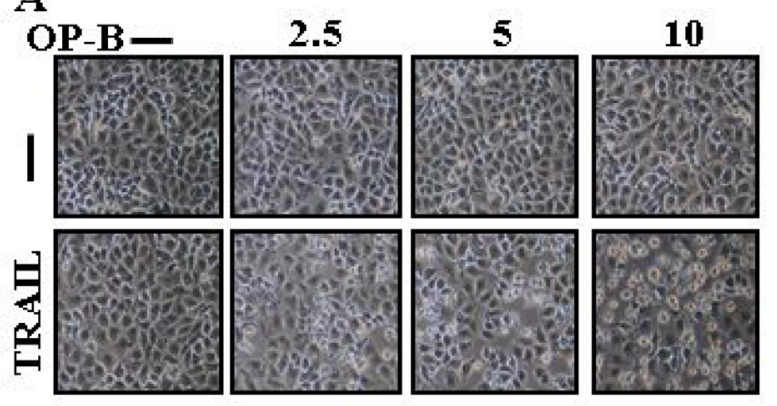

B
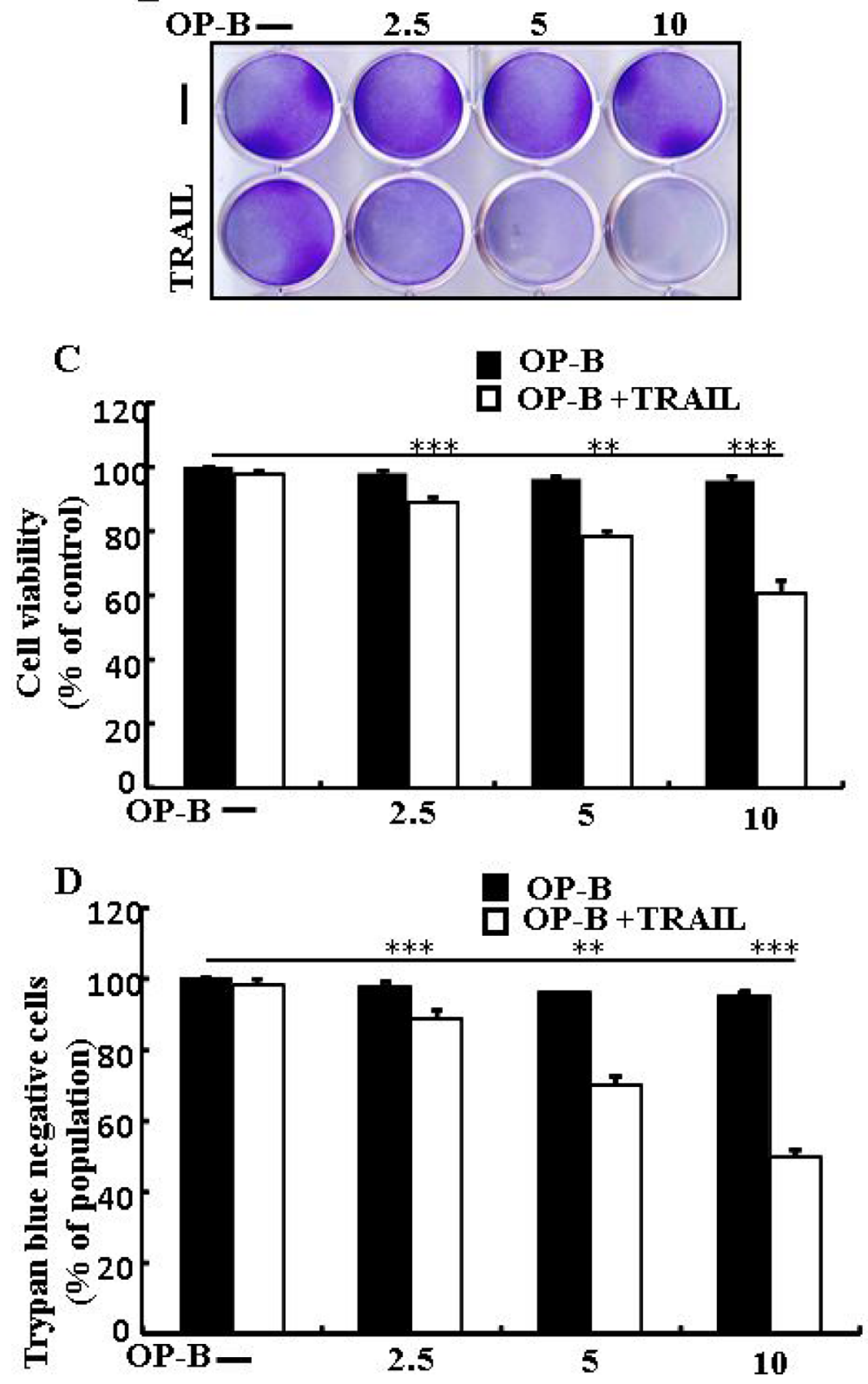

Figure 1: Ophiopogonin B sensitizes TRAIL-initiated apoptosis in A549cells. A549cells were pre-incubated with Ophiopogonin B at different doses $(0,2.5,5$, and $10 \mu \mathrm{M})$ for $12 \mathrm{~h}$ and exposed to TRAIL protein $200 \mathrm{ng} / \mathrm{ml}$ for $2 \mathrm{~h}$. (A) Cell morphology photographed using light microscope $(\times 100)$; (B) Cell viability was measured with crystal violet assay; (C) Bar graph indicating the average density of crystal violet; (D) Cell viability was assessed with trypan blue dye exclusion assays. ${ }^{* * *} p<0.01,{ }^{* * * *} p<0.001$ : represent significant differences between control and each treatment group; OP-B: Ophiopogonin B; TRAIL: Tumor necrosis factor (TNF)-related apoptosis-inducing ligand. 
Nevertheless, co-treatment of TRAIL, Ophiopogonin B and chloroquine diminished the increase in expression (Figure 4D). These findings revealed that Ophiopogonin B-arbitrated enhancement of TRAIL-initiated apoptosis could be enclosed by chloroquine by autophagy flux incitation.

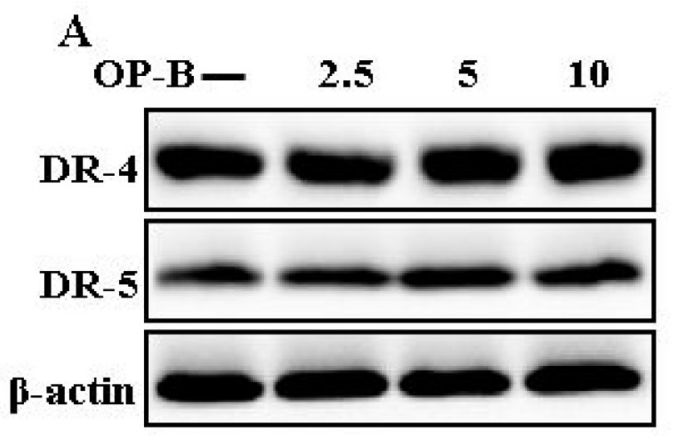

L.

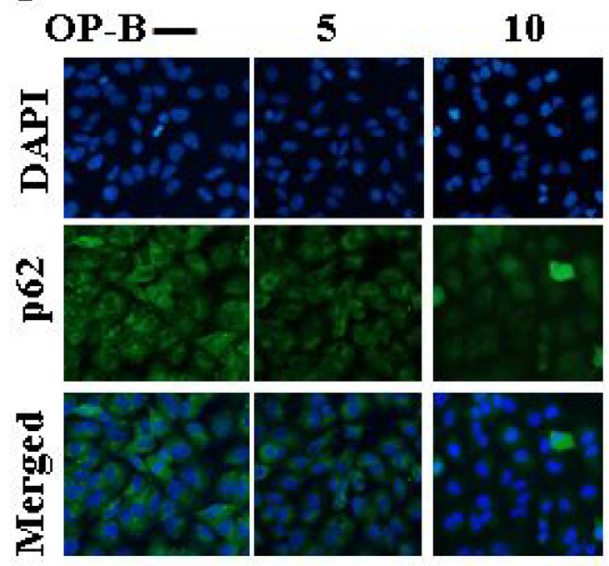

Ophiopogonin B-sensitized TRAIL-initiated apoptosis is enclosed by genetic attenuation of autophagy flux

As demonstrated in, co-treatment of ATG5 siRNA, Ophiopogonin B and TRAIL enclosed cell death.
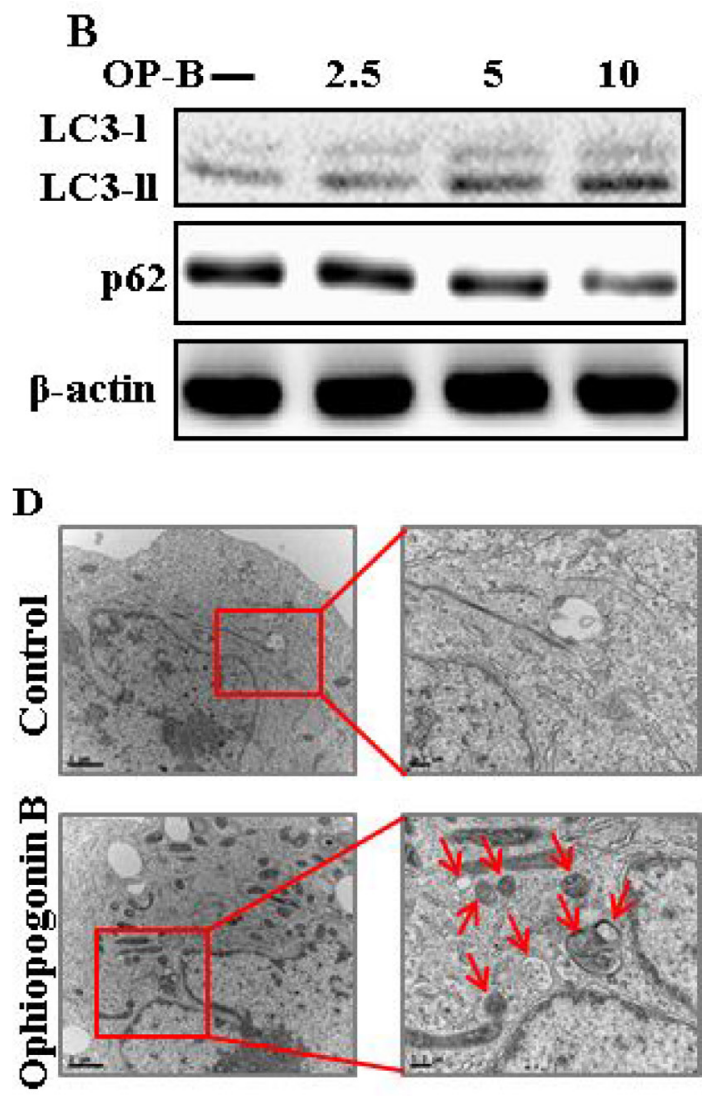

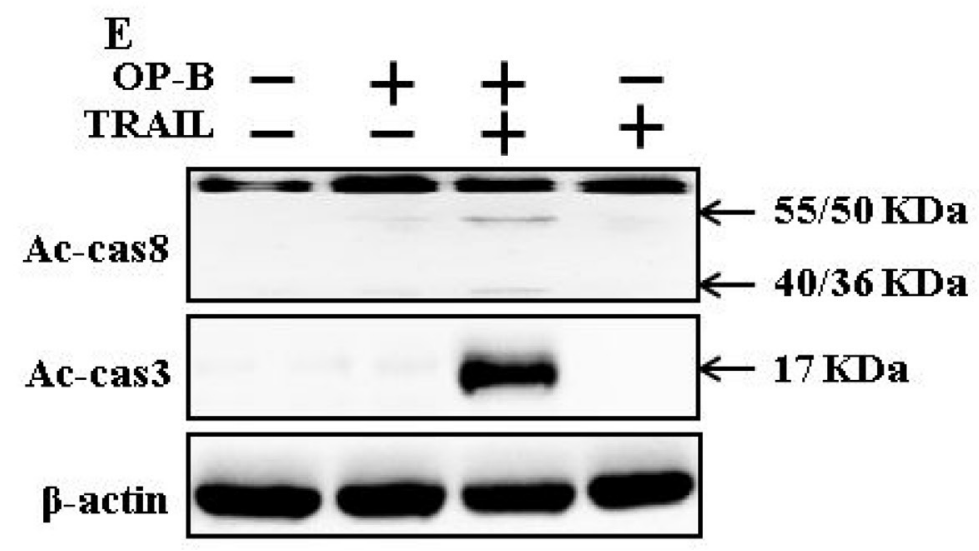

Figure 2: Ophiopogonin B induces autophagy and sensitizes cells to apoptosis arbitrated by TRAIL. A549 cells were pre-incubated with Ophiopogonin B at varying doses $(0,2.5$, 5, and $10 \mu \mathrm{M})$ for 12 h. (A and B) Western blot for DR-4, DR-5, LC3-II, and p62 proteins was analyzed from A549 cells; (C) Cells were immunostained with p62 antibody (green) and assessed in fluorescent view; (D) TEM displaysthe ultrastructure of cells treated with Ophiopogonin B $(10 \mu \mathrm{M})$ for $12 \mathrm{~h}$. Arrows indicate autophagosomes, together with residual digested material and emptyvacuoles; (E) Western blot for Ac-cas3 and Ac-cas8 expression levels was conducted with A549 cells. Cells were pre-incubated with Ophiopogonin B $(10 \mu \mathrm{M})$ for $12 \mathrm{~h}$ and exposed toTRAIL protein for an exceeding $1 \mathrm{~h}$. $\beta$-actin was used as the loading control. OP-B: Ophiopogonin B; TRAIL: Tumor necrosis factor (TNF)-related apoptosis-inducing ligand; Ac-cas3: Activated caspase 3; Ac-cas8: Activated caspase 8. 
Morphological consequences confirmed that ATG5 siRNA enclosed the cell death compared to Ophiopogonin B, TRAIL, and NC (Figure 5A). Co-treatment with TRAIL, Ophiopogonin B, and ATG5 siRNA attenuated cell death with strongly increased viability (Figure 5B-5D). These findings revealed that ATG5 siRNA could block Ophiopogonin B-arbitrated cell death initiated by TRAIL.
Genetic attenuation of autophagy encloses TRAIL-initiated apoptosis by Ophiopogonin B via autophagy flux incitation

The expression of DR4 and DR5 were unaltered by Ophiopogonin $\mathrm{B}$ alone or by combined regimen (Figure 6A). Knockdown of ATG5 attenuated
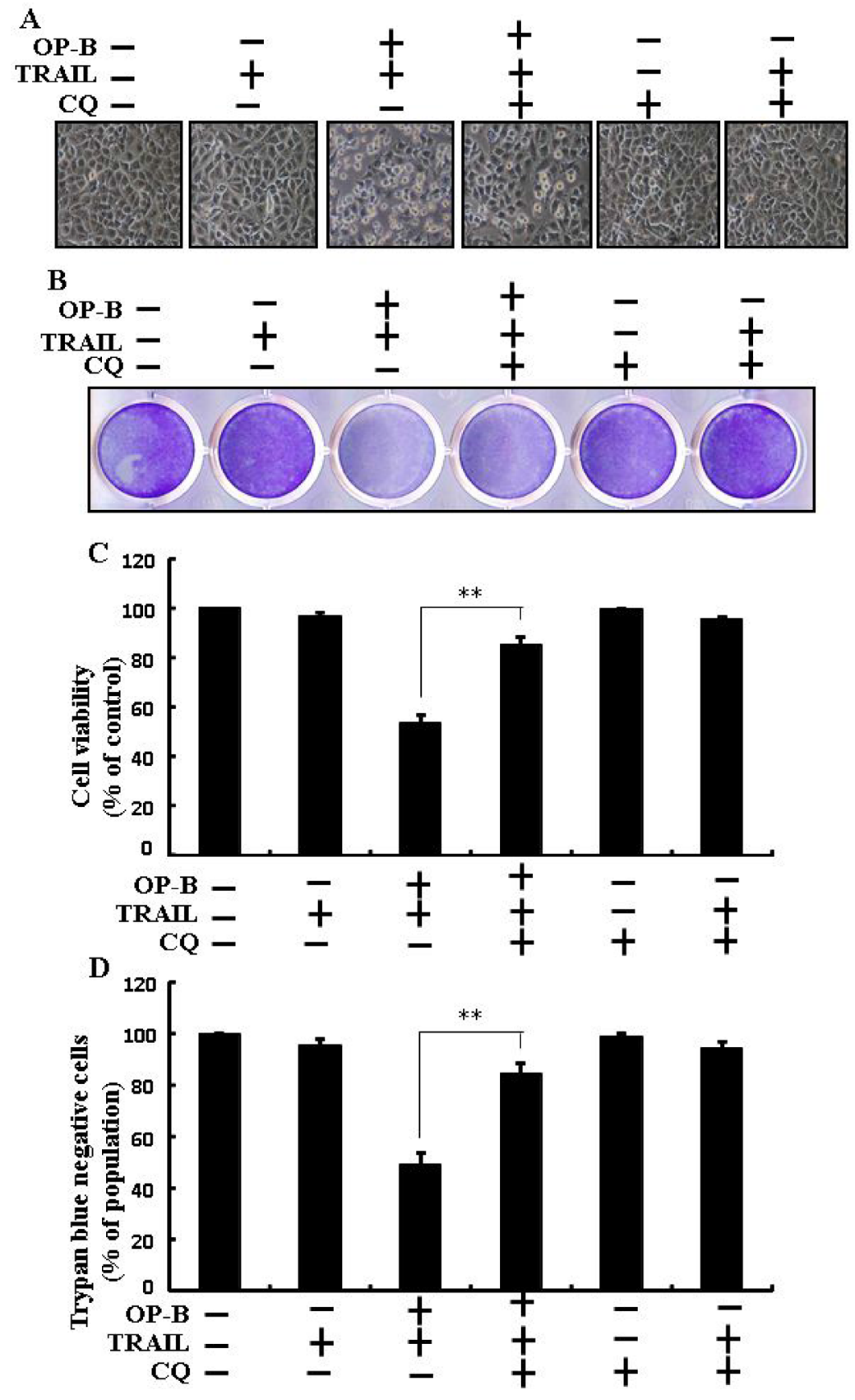

Figure 3: Ophiopogonin B-mediated enhancement of TRAIL-initiated apoptosis is enclosed by attenuation of autophagy. Cells were pre-incubated with the indicated Ophiopogonin B $(10 \mu \mathrm{M})$ doses for $12 \mathrm{~h}$ and exposed to TRAIL protein for an additional $2 \mathrm{~h}$. Additional cells were also pre-incubated with autophagy inhibitor chloroquine for $1 \mathrm{~h}$ followed by Ophiopogonin B treatment. (A) Cell morphology photographed using light microscope $(\times 100)$; (B) Cell viability was measured with crystal violet assay; (C) Bar graph indicating average density of crystal violet; (D) Cell viability was assessed with trypan blue dye exclusion assays. ${ }^{* *} p<0.01$ :represent significant differences between control and each treatment group; OP-B: Ophiopogonin B; TRAIL: Tumor necrosis factor (TNF)-related apoptosis-inducing ligand; CQ: Chloroquine. 
Ophiopogonin B- initiated LC3-II and markedly increased p62 protein levels (Figure 6B). Immunofluorescent staining findings also revealed this p62 protein level (Figure 6C). Nevertheless, co-treatment with TRAIL, ATG5 siRNA and Ophiopogonin B diminished the increase in Ac-cas3 and Ac-cas8 (Figure 6D). These data confirmed that Ophiopogonin B-arbitrated enhancement of TRAIL-initiated apoptosis could be enclosed by genetic attenuation of autophagy flux.

\section{Downregulation of c-FLIP by Ophiopogonin B attenuates TRAIL resistance}

Western blot and Immunofluorescent staining finding revealed that Ophiopogonin B (Figure 7A and 7B) attenuated the expression of c-FLIP. Combined regimen of Ophiopogonin B and TRAIL decreased c-FLIP levels
(Figure 7C). Basically, c-FLIP expression was increased by chloroquine when co-treated with Ophiopogonin B (Figure 7D). Furthermore, combined regimen of ATG5siRNA and Ophiopogonin B increased c-FLIP levels (Figure 7E). These finding revealed that Ophiopogonin B downregulates c-FLIP and sensitizes TRAIL-initiated apoptosis by inciting autophagy flux.

\section{Ophiopogonin B sensitizes TRAIL-initiated apoptosis in HCC-15 and Calu-3 cells}

We visualized these cells using a microscope to supervise the morphological alteration. Treatment of TRAIL or Ophiopogonin B alone marginally commenced cell death (Figure 8). Moreover, combined regimen of TRAIL with Ophiopogonin B strongly attenuated viability compared with TRAIL
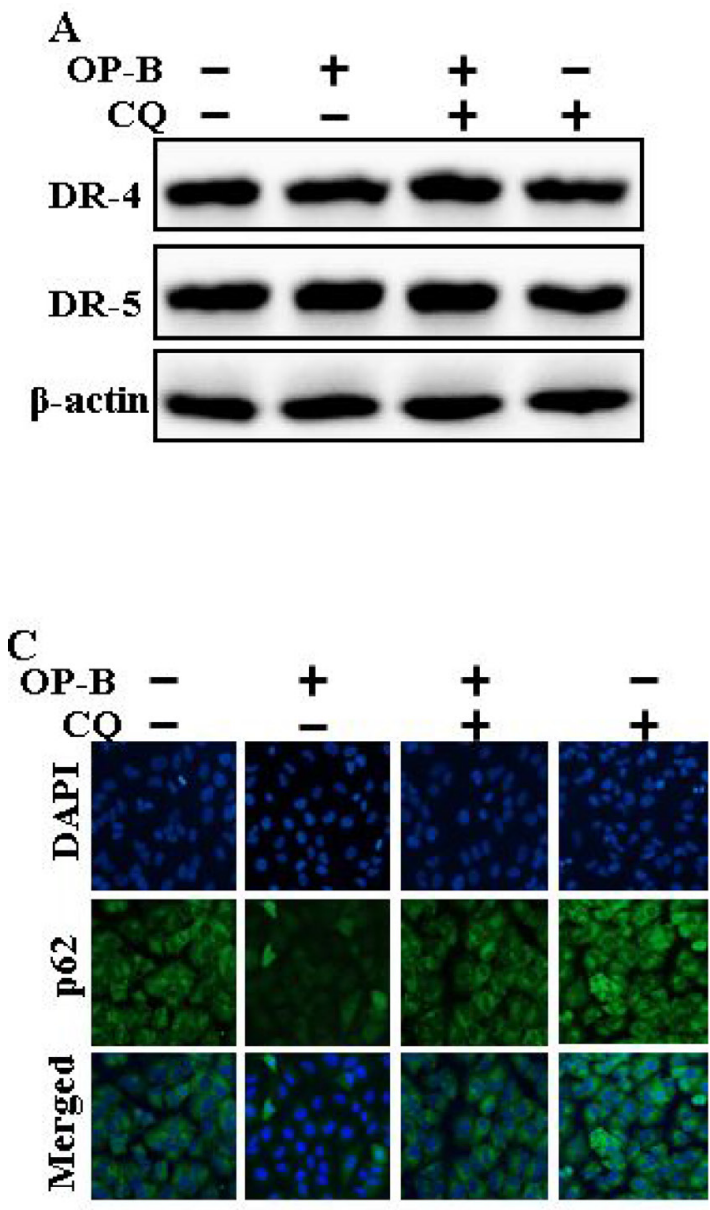
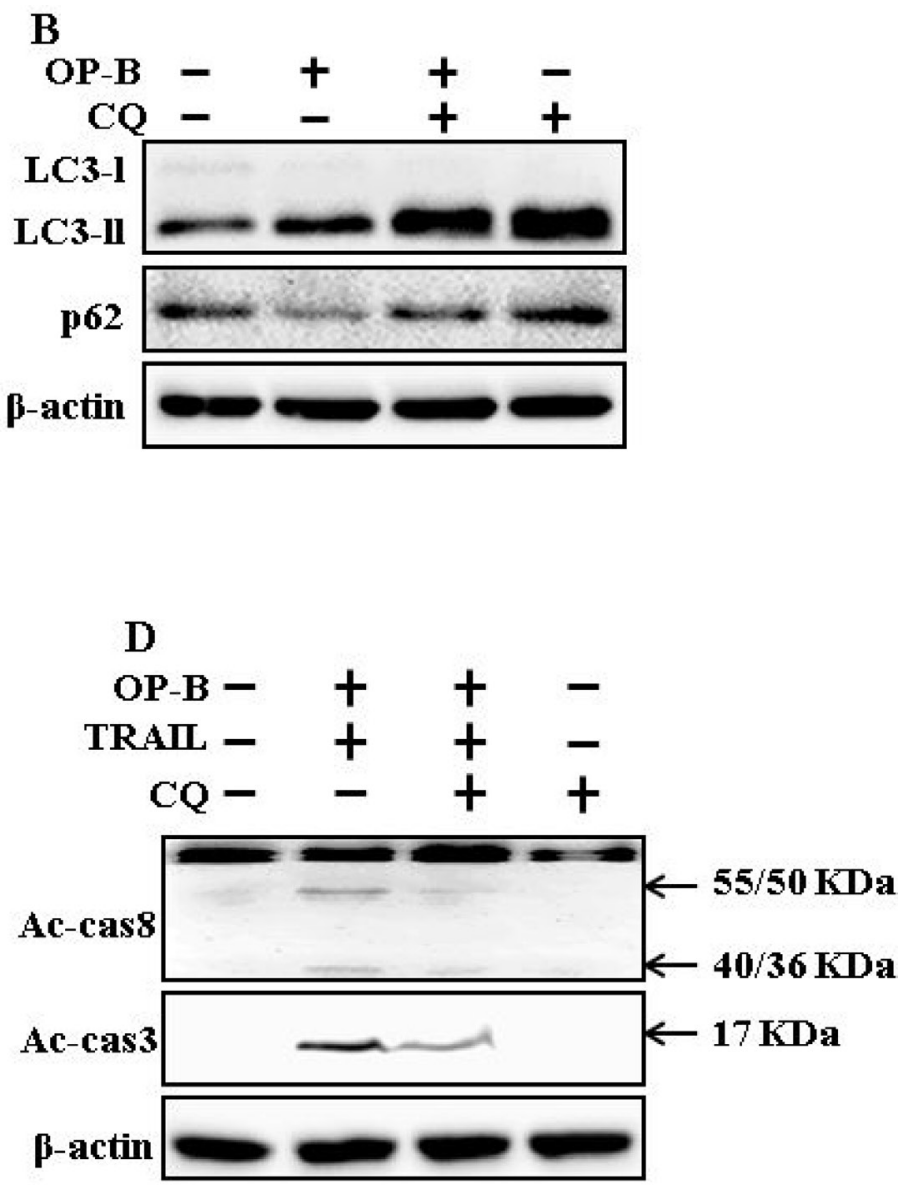

Figure 4: Attenuation of autophagy encloses TRAIL-arbitrated apoptosis sensitized by Ophiopogonin B via incitation of autophagy flux. A549 cells were pre-incubated with chloroquine for $1 \mathrm{~h}$ followed by indicated Ophiopogonin B (10 $\mu \mathrm{M})$ doses for 12 h. (A and B) Western blot for DR-4, DR-5, LC3-II, and p62 proteins was analyzed from A549 cells; (C) Cells were immunostained with p62 antibody (green) and assessed in fluorescent view; (D) Western blot for Ac-cas3 and Ac-cas8 expression levels was conducted with A549 cells. Cells were pre-incubated with the indicated Ophiopogonin B $(10 \mu \mathrm{M})$ concentrations for $12 \mathrm{~h}$ and exposed to TRAIL protein for an additional $1 \mathrm{~h}$. Additional cells were pre-incubated with autophagy inhibitor chloroquine for $1 \mathrm{~h}$, followed by Ophiopogonin B treatment. $\beta$-actin was used as the loading control. OP-B: Ophiopogonin B; Tumor necrosis factor (TNF)-related apoptosis-inducing ligand; Ac-cas3: Activated caspase 3; Ac-cas8: Activated caspase 8; CQ: Chloroquine. 
or Ophiopogonin $\mathrm{B}$ alone (Figure $8 \mathrm{~B}, 8 \mathrm{C}, 8 \mathrm{E}$, and $8 \mathrm{~F})$. These finding revealed that Ophiopogonin B significantly elevated TRAIL-initiated apoptosis in HCC-15 and Calu-3 cells.

\section{DISCUSSION}

Drug resistance is a major barrier in anticancer chemotherapy. Combined chemotherapy using drugs with disparate mechanisms of function may raise anticancer efficacy [25]. Ideal agents for chemotherapy are those that can discriminately kill cancer cells without harming normal cells. TRAIL is a dynamic chemotherapeutic candidate because of its tremendous anticancer mobility in diverse cancer characters and it asserts minimum cytotoxic outcomes on the vast majority of normal cells [26, 27]. TRAIL has a significant advantage in its selectivity for targeting tumor cells owing to their comparatively

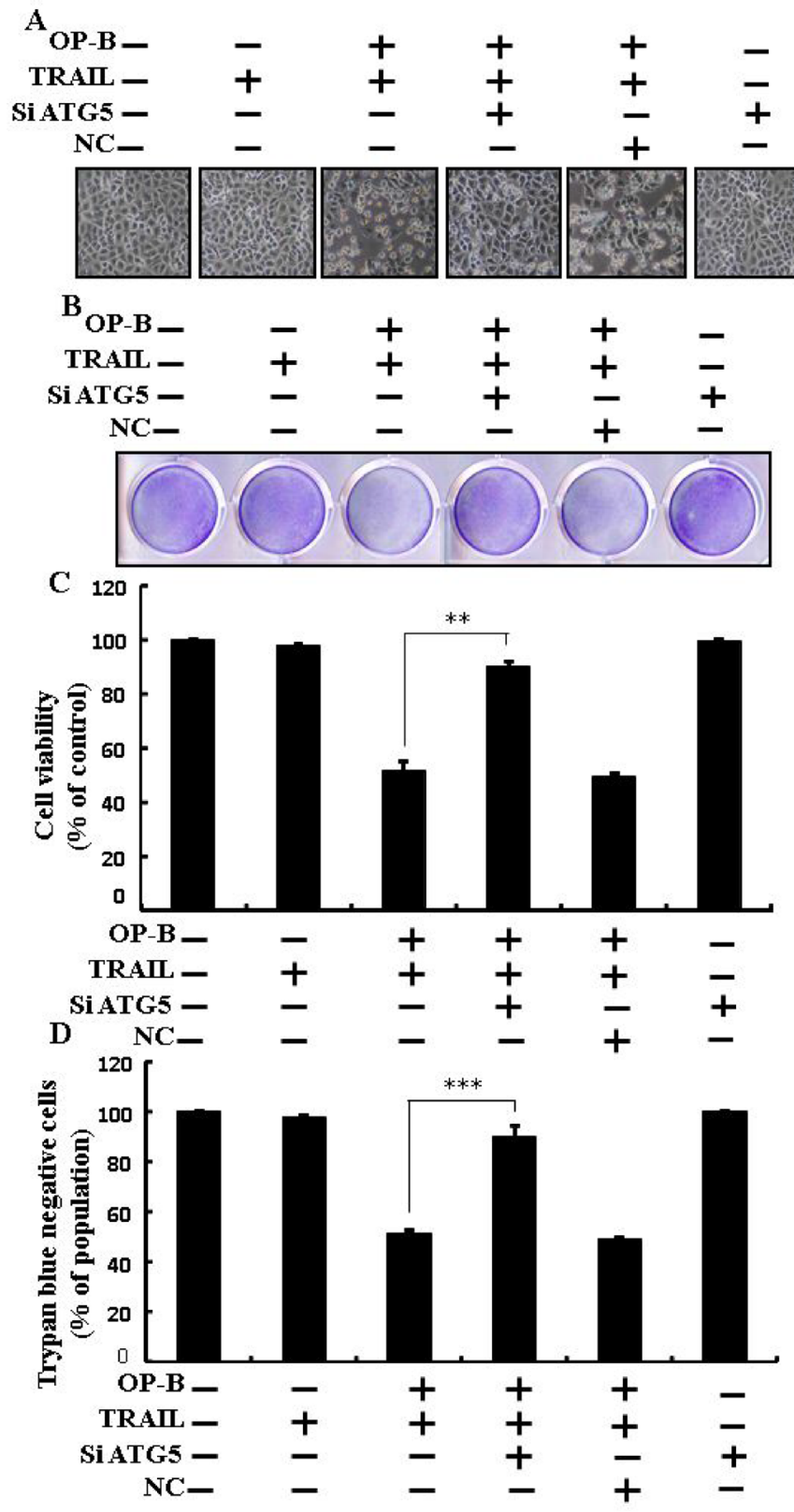

Figure 5: Ophiopogonin B sensitized TRAIL-initiated apoptosis is encloseed by genetic attenuation of autophagy flux. A549 cells were pre-incubated with ATG5 siRNA or negative control siRNA for $24 \mathrm{~h}$ and then exposed to indicated Ophiopogonin B (10 $\mu \mathrm{M})$ doses for $12 \mathrm{~h}$ with or without TRAIL protein for an additional $2 \mathrm{~h}$. (A) Cell morphology photographed using light microscope $(\times 100)$; (B) Cell viability was measured with crystal violet assay; (C) Bar graph indicating average density of crystal violet; (D) Cell viability was assessed with trypan blue dye exclusion assays. ${ }^{* *} p<0.01,{ }^{* * *} p<0.001$ :represent significant differences between control and each treatment group. OP-B: Ophiopogonin B; TRAIL: Tumor necrosis factor (TNF)-related apoptosis-inducing ligand; siATG5: ATG5 small interfering RNA; NC: Negative control. 
higher expression of death receptors than normal cells [6]. Cancer cells acquire resistance by downregulating death receptors and upregulating anti-apoptotic proteins including c-FLIP [28]. Ophiopogonin B, a natural product derived from Ophiopogon japonicus, has been widely used in Chinese traditional medicine [29]. Autophagy is cellular degradation process by which cytoplasmic components and organelles are enveloped into the autophagosome and transported into the lysosome to assimilate cytoplasmic debris and maintain cellular homeostasis [30]. Formation of the autophagosome and LC3-I-phospholipid links LC3II. P62 is accumulates in autophagosomes by specific interaction with LC3, and is easily decayed during autophagy. Suppressing autophagy findings in quick aggregation of p62, and attenuated p62 linked by inciting autophagy [31]. Autophagy maintains a dual function in apoptosis, acting as either a suppressor or a promoter of apoptosis [32].

Recently shown that A549 cells were particularly resistant to TRAIL-initiated apoptosis [33]. In our research focused that TRAIL or Ophiopogonin B alone induced apoptosis slightly or not at all (Figure 1). Some papers have revealed that Ophiopogonin B attenuated cancer cell propagation and adoption of autophagy [16]. Our findings indicated that LC3-II level was elevated and that of p62 was attenuated after Ophiopogonin B regimen (Figure 2). Our findings also confirmed that the diacritic pharmacological (Figures 3 and 4) and genetic autophagy blocker enclosed
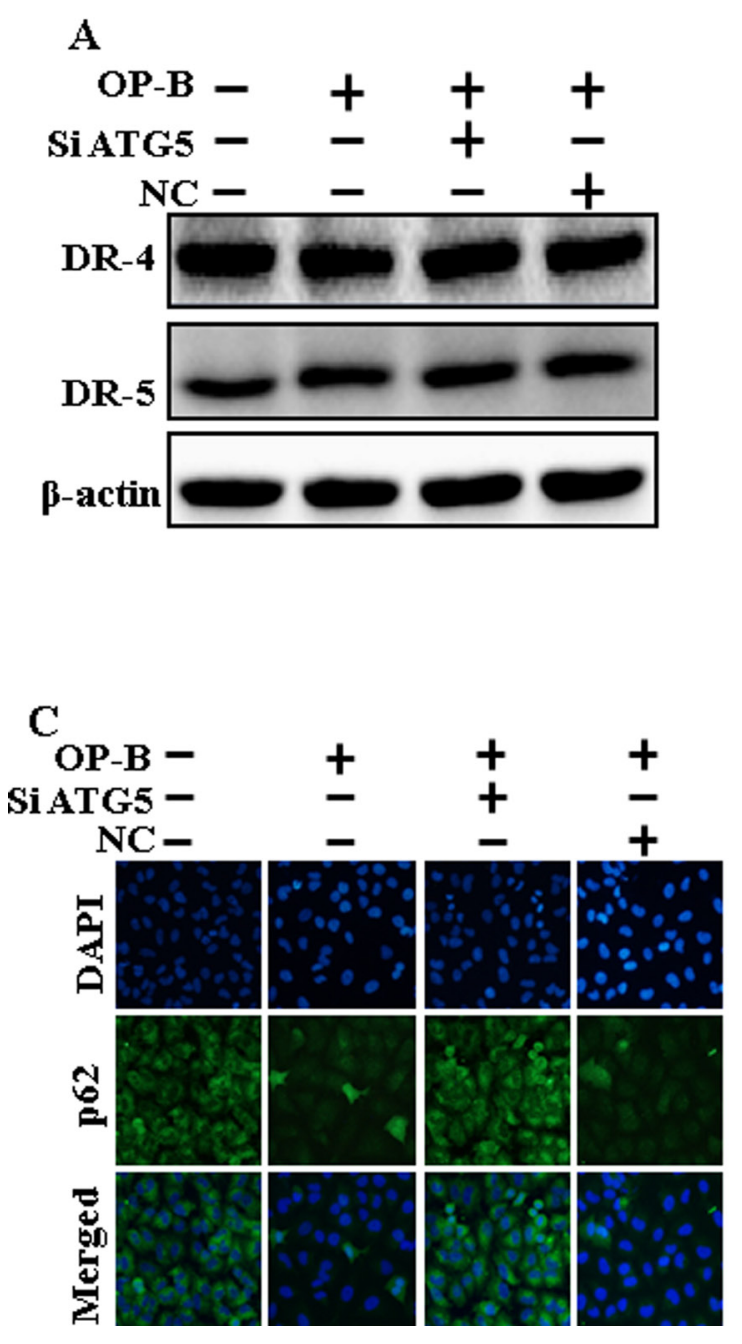

B

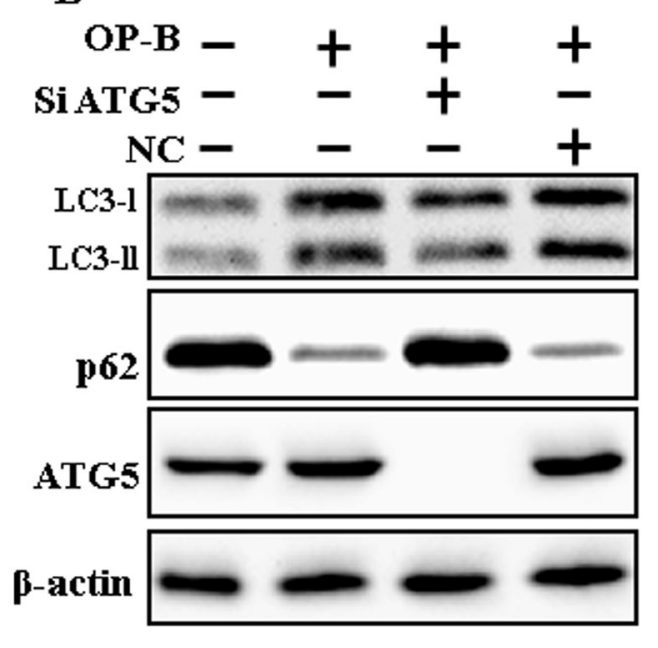

D

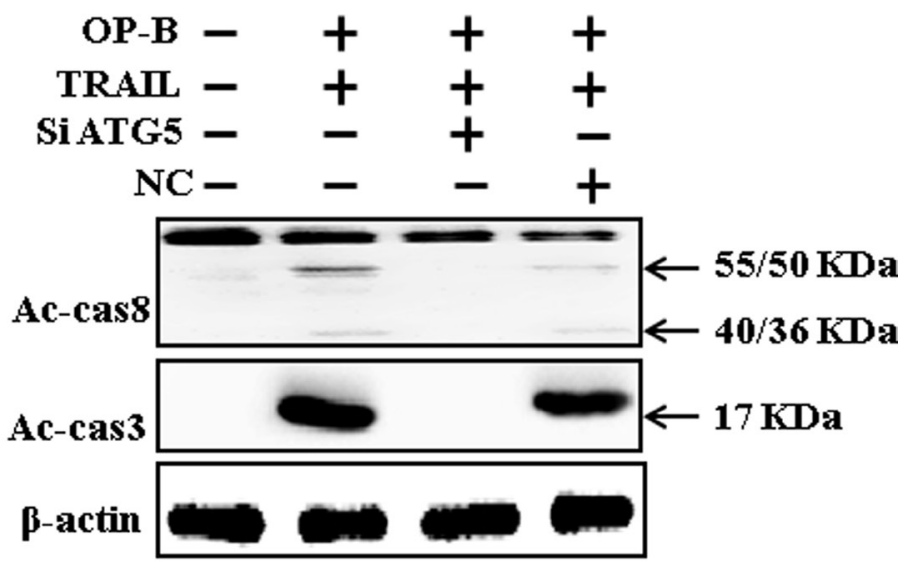

Figure 6: Genetic attenuation of autophagy encloses TRAIL-initiated apoptosis by Ophiopogonin B via autophagy flux incitation. A549 cells were pre-incubated with ATG5siRNA or negative control siRNA for $24 \mathrm{~h}$, and then exposed to indicated Ophiopogonin B doses $(10 \mu \mathrm{M})$ for $12 \mathrm{~h}$. (A and B) Western blot for DR-4, DR-5, LC3-II, p62 and ATG5 proteins was analyzed from A549 cells; (C) Cells were immunostained with p62 antibody (green) and assessed in fluorescent view; (D) Western blot for Ac-cas3 and Ac-cas8 expression levels was conducted. A549 cells were pre-incubated with ATG5siRNA or negative control siRNA for 24 h, and then exposed to indicated Ophiopogonin B $(10 \mu \mathrm{M})$ doses for $12 \mathrm{~h}$ with or without TRAIL protein for an additional $1 \mathrm{~h}$. $\beta$-actin was used as the loading control. OP-B: Ophiopogonin B; TRAIL: Tumor necrosis factor (TNF)-related apoptosis-inducing ligand; Ac-cas3: Activated caspase 3; Ac-cas8: Activated caspase 8; siATG5: ATG5 small interfering RNA; NC: Negative control. 
Ophiopogonin B-arbitrated apoptosis initiated by TRAIL (Figures 5 and 6). Some reports have demonstrated that drug-induced autophagy and downregulation of c-FLIP promotes apoptosis in lung adenocarcinoma cells $[34,35]$. Our results also suggested that Ophiopogonin B downregulates c-FLIP and could sensitize TRAILinitiated cell death by inciting autophagy flux (Figure 7). In summary, attenuation of c-FLIP by Ophiopogonin B sensitizes TRAIL-initiated apoptosis in A549 tumor cells via autophagy flux. Combined regimen with Ophiopogonin $\mathrm{B}$ and TRAIL could be a moderate therapeutic method for careful treatment of some TRAIL-resistant cancers.

\section{MATERIALS AND METHODS}

\section{Cell culture}

Cancer cells originating from human lung (A549,HCC-15andCalu-3)tumors were attained from the American Type Culture Collection (Global Bioresource
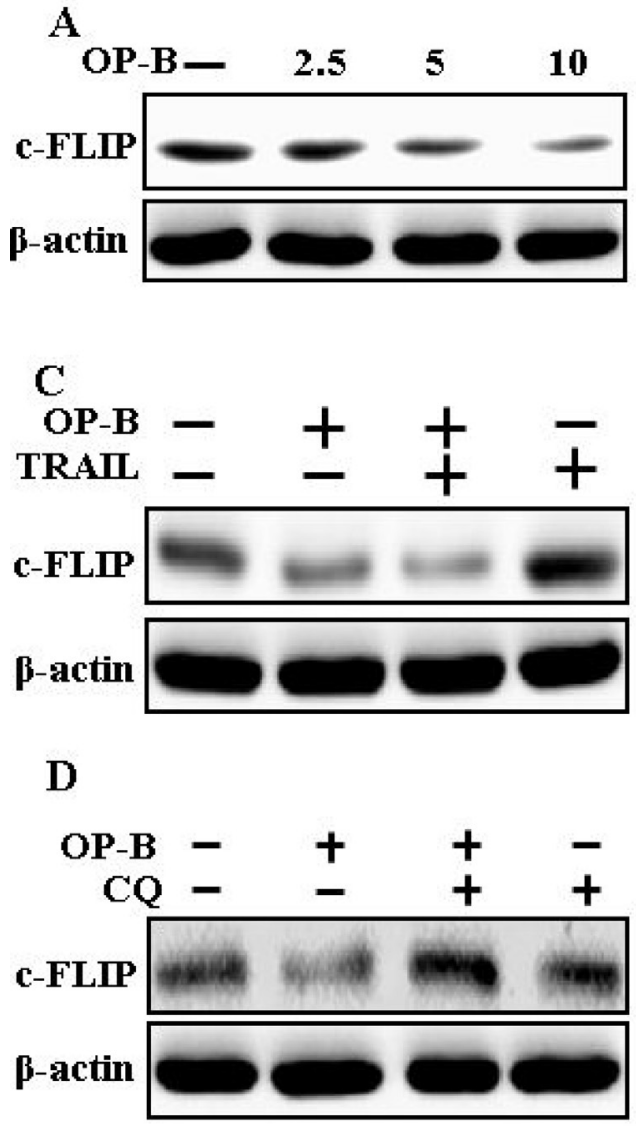

Center, Manassas, VA, USA). Cells were maintained in RPMI-1640(Gibco BRL, Grand Island, NY, USA) medium bearing $10 \%$ fetal bovine serum and $100 \mu \mathrm{g} / \mathrm{ml}$ penicillinstreptomycin. Cells were cultured at $37^{\circ} \mathrm{C}$ and $5 \% \mathrm{CO}_{2}$ in a humidified incubator.

\section{Reagents}

Recombinant Ophiopogonin B was purchased from chem faces (CheCheng Rd, WETDZ, Wuhan, Hubei 430056, PRC), chloroquine $(20 \mu \mathrm{M})$ was purchased from Sigma-Aldrich (St. Louis, MO, USA). Recombinant TRAIL (200 ng/ml) was acquired from Abfrontier (Geumcheon-gu, Seoul, South Korea).

\section{Cell viability assay}

A549, HCC-15and Calu-3 cells were plated at $1.0 \times$ $10^{4}$ cells/well in 12 -well plates and incubated at $37^{\circ} \mathrm{C}$ for $24 \mathrm{~h}$. The A549cells were pretreated with Ophiopogonin B

B

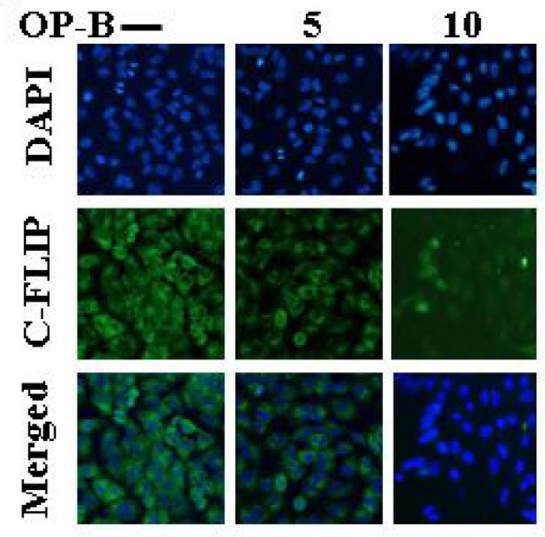

\section{E}

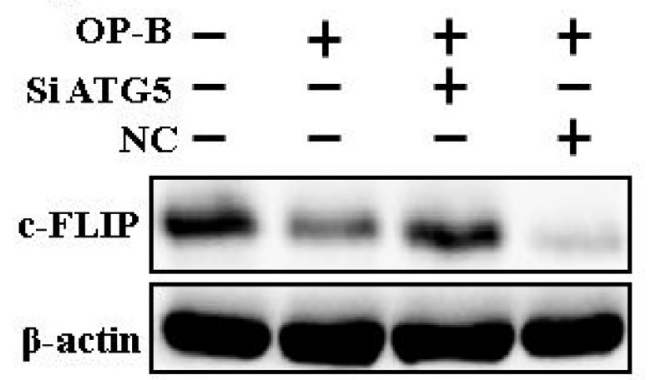

Figure 7: Downregulation of c-FLIP by Ophiopogonin B attenuates TRAIL resistance. A549 cells were pre-incubated with varying concentrations of Ophiopogonin B $(0,2.5,5$, and $10 \mu \mathrm{M})$ for $12 \mathrm{~h}$ and exposed to TRAIL for $1 \mathrm{~h}$. (A-C) Cells were harvested and assessed by Western blotting and immunofluorescent staining to determine the expression of c-FLIP; (D) c-FLIP expression levels emerged on western blot analysis. A549 cells were pre-incubated with chloroquine for $1 \mathrm{~h}$ followed by Ophiopogonin B (10 $\mu \mathrm{M})$ treatment for $12 \mathrm{~h}$; (E) Expression levels of c-FLIP emerged on western blot analysis. A549 cells were pre-incubated with ATG5 siRNA or NC siRNA for $24 \mathrm{~h}$ followed by Ophiopogonin B $(10 \mu \mathrm{M})$ treatment for $12 \mathrm{~h}$ with or without $200 \mathrm{ng} / \mathrm{ml}$ TRAIL for an exceeding $1 \mathrm{~h}$. $\beta$-actin was used as loading control. OP-B: Ophiopogonin B; c-FLIP :cellular FLICE -like inhibitory protein; CQ: Chloroquine; TRAIL: Tumor necrosis factor (TNF)-related apoptosis-inducing ligand; siATG5: ATG5 small interfering RNA; NC: Negative control. 
in a dose-dependent manner $(0,2.5,5$, and $10 \mu \mathrm{M})$. After pretreated with different doses of Ophiopogonin B for $12 \mathrm{~h}$ and were treated with TRAIL protein for an additional $2 \mathrm{~h}$. Additional cells were also pretreated with chloroquine $(20 \mu \mathrm{M})$ for $1 \mathrm{~h}$, followed by Ophiopogonin B treatment. Cell morphology was examined by photographs under the inverted microscopy (Nikon, Japan). Cell viability was determined applying crystal violet staining method as previously described [25].

\section{Trypan blue exclusion assay}

The number of cell viability was investigated by trypan blue dye exclusion assay (Sigma-Aldrich) using a hemocytometer.

\section{Western blot assay}

A549 cell lysates were prepared by harvesting, washing in cold PBS, resuspending in lysis buffer followed by sonication. Proteins $(35 \mu \mathrm{g})$ were resolved by $10 \%-15 \%$ SDS gels and transferred to a nitrocellulose membrane, and analyzed by western blotting as described previously [26]. The antibodies were used : LC3 (Novus Biologicals, Littleton, CO, USA), DR-4, DR-5, and $ß$-actin Sigma-Aldrich (St. Louis, MO, USA), p62ATG5, cleaved caspase-3(Cell Signaling Technology, Danvers, MA, USA), c-FLIP (Enzo life sciences, USA), cleaved caspase-8 (BD pharmingen, USA).

\section{Immunofluorescent staining}

A549 cell lines cultured on glass coverslips positioned on a 24-well plate. The cells were washed with PBS and adjusted with 4\% paraformaldehyde for $15 \mathrm{~min}$ at room temperature. Following this, Cells were then washed twice with ice-cold PBS, blocked with 5\% FBS in Tris-buffered saline with Tween, and incubated with monoclonal antibodies against p62,cFLIP at room temperature for $24 \mathrm{~h}$. Unbound antibody was removed with PBS wash ( three times) and Cells were then incubated again with secondary antibody at
A

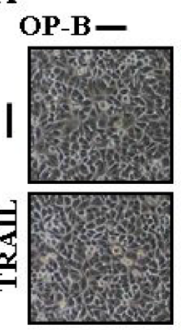

B
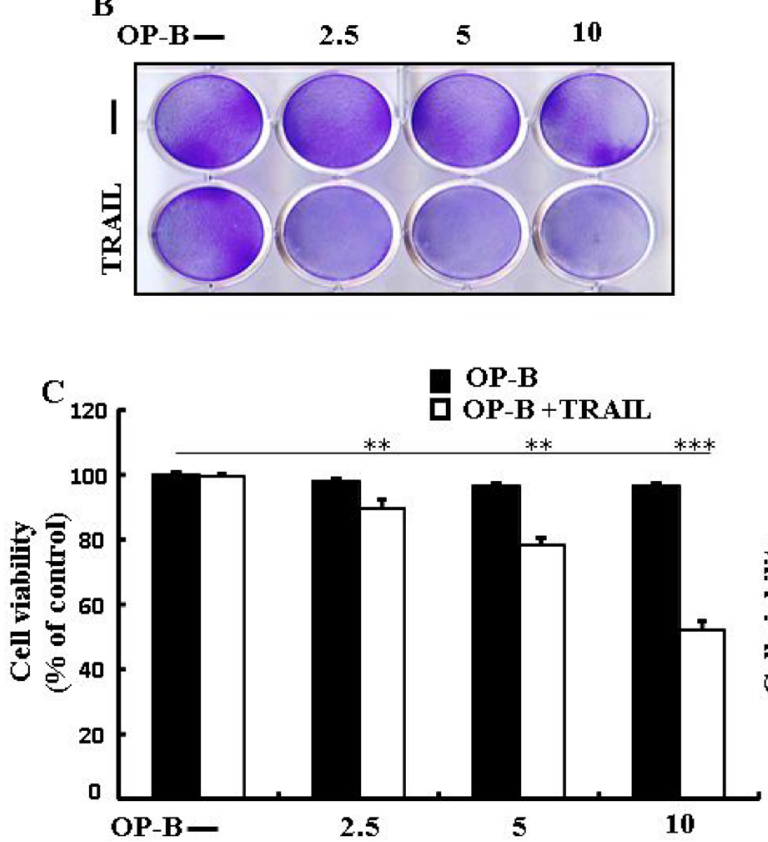

D
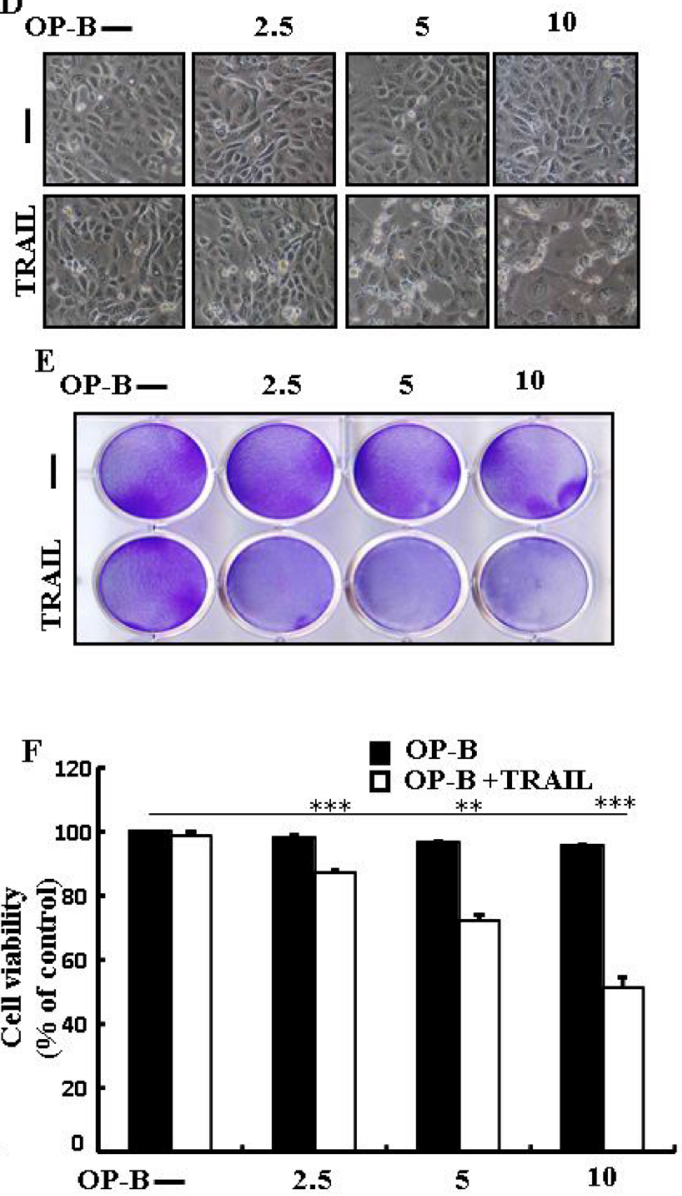

Figure 8: Ophiopogonin B sensitizes TRAIL-initiated apoptosis in HCC-15 and Calu-3 cells. HCC-15 and Calu3 pre-incubated with varying concentrations of Ophiopogonin $\mathrm{B}(0,2.5,5$, and $10 \mu \mathrm{M})$ for $12 \mathrm{~h}$ and exposed to TRAIL for $2 \mathrm{~h}$. (A and D) Cell morphology photographed under light microscope $(\times 100)$; (B and E) Cell viability determined with crystal violet assay; $(\mathbf{C}$ and $\mathbf{F})$ Bar graph showing the average density of crystal violet dye; ${ }^{* *} p<0.01,{ }^{* * *} p<0.001$ : represent significant differences between control and each treatment group; OP-B: Ophiopogonin B; TRAIL: Tumor necrosis factor (TNF)-related apoptosis-inducing ligand. 
room temperature for $2 \mathrm{~h}$ in the dark. Finally, cells were mounted with DakoCytomation fluorescent mounting medium and visualized via a fluorescence microscopy.

\section{TEM (Transmission Electron Microscopy) analysis}

TEM samples were examined by Transmission Electron Microscope (JEM-2010, JEOL) installed in the Center for University-Wide Research Facilities (CURF) at Chonbuk National University. After fixation ofA549 cell samples in 2\% glutaraldehyde and $2 \%$ paraformaldehyde in 0.05 sodium cacodylate buffer, specimens were post fixed in $1 \%$ osmium tetroxide, dehydrated in graded ethanol and propylene oxide. A549 cells were embedded in Epoxy resin. Ultrathin sections were cut on an LKB-III ultratome and were stained with $0.5 \%$ uranyl acetate and lead citrate. The images were taken on a Hitachi H7650 electron microscope at an accelerating voltage of $100 \mathrm{kV}$.

\section{RNA interference}

A549 cells were transfected with ATG5-specific small interfering RNA (siRNA; oligo ID HSS114103; Invitrogen, Carlsbad, CA, USA) using Lipofectamine 2000 according to the manufacturer's instructions. After 36-h post transfection, the knockdown efficiency at protein level was observed by immunoblotting and cell viability test. Nonspecific siRNA was used as a negative control.

\section{Statistical analysis}

All data are expressed as means \pm standard deviation (SD) and were compared using the Student's $t$-test, analysis of variance and the ANOVA Duncan test using SAS statistical package (SAS Institute, Cary, NC, USA). Statistical significance was indicated by a $P$ value less than $0.01(* *)$, or $0.001(* * *)$.

\section{ACKNOWLEDGMENTS}

This study was supported by a grant from the National Research Foundation of Korea (NRF), funded by the Korean government (2016R1A2B2009293).

\section{CONFLICTS OF INTEREST}

The authors declare no conflicts of interest.

\section{REFERENCES}

1. Seiwert TY, Connell PP, Mauer AM, Hoffman PC, George CM, Szeto L, Salgia R, Posther KE, Nguyen B, Haraf DJ, Vokes EE. A phase I study of pemetrexed, carboplatin, and concurrent radiotherapy in patients with locally advanced or metastatic non-small cell lung or esophageal cancer. Clin
Cancer Res. 2007; 13:515-22. https://doi.org/10.1158/10780432.ccr-06-1058.

2. Ettinger DS, Akerley W, Borghaei H, Chang AC, Cheney RT, Chirieac LR, D'Amico TA, Demmy TL, Ganti AK, Govindan R, Grannis FW Jr, Horn L, Jahan TM, et al. Nonsmall cell lung cancer. J Natl Compr Canc Netw. 2012; 10:1236-71.

3. McGuire S. World Cancer Report 2014. Geneva, Switzerland: World Health Organization, International Agency for Research on Cancer, WHO Press, 2015. Adv Nutr. 2016; 7:418-9. https://doi.org/10.3945/an.116.012211.

4. Wiley SR, Schooley K, Smolak PJ, Din WS, Huang CP, Nicholl JK, Sutherland GR, Smith TD, Rauch C, Smith $\mathrm{CA}$. Identification and characterization of a new member of the TNF family that induces apoptosis. Immunity. 1995; 3:673-82.

5. Pitti RM, Marsters SA, Ruppert S, Donahue CJ, Moore A, Ashkenazi A. Induction of apoptosis by Apo-2 ligand, a new member of the tumor necrosis factor cytokine family. J Biol Chem. 1996; 271:12687-90.

6. Ashkenazi A, Pai RC, Fong S, Leung S, Lawrence DA, Marsters SA, Blackie C, Chang L, McMurtrey AE, Hebert A, DeForge L, Koumenis IL, Lewis D, et al. Safety and antitumor activity of recombinant soluble Apo2 ligand. J Clin Invest. 1999; 104:155-62. https://doi.org/10.1172/ jci6926.

7. Oldenhuis CN, Stegehuis JH, Walenkamp AM, de Jong $\mathrm{S}$, de Vries EG. Targeting TRAIL death receptors. Curr Opin Pharmacol. 2008; 8:433-9. https://doi.org/10.1016/j. coph.2008.06.011.

8. Kischkel FC, Hellbardt S, Behrmann I, Germer M, Pawlita M, Krammer PH, Peter ME. Cytotoxicity-dependent APO-1 (Fas/CD95)-associated proteins form a death-inducing signaling complex (DISC) with the receptor. Embo j. 1995; 14:5579-88.

9. Sprick MR, Weigand MA, Rieser E, Rauch CT, Juo P, Blenis J, Krammer PH, Walczak H. FADD/MORT1 and caspase- 8 are recruited to TRAIL receptors 1 and 2 and are essential for apoptosis mediated by TRAIL receptor 2 . Immunity. 2000; 12:599-609.

10. Kischkel FC, Lawrence DA, Chuntharapai A, Schow P, Kim KJ, Ashkenazi A. Apo2L/TRAIL-dependent recruitment of endogenous FADD and caspase- 8 to death receptors 4 and 5 . Immunity. 2000; 12:611-20.

11. Safa AR. c-FLIP, a master anti-apoptotic regulator. Exp Oncol. 2012; 34:176-84.

12. Irmler M, Thome M, Hahne M, Schneider P, Hofmann K, Steiner V, Bodmer JL, Schroter M, Burns K, Mattmann C, Rimoldi D, French LE, Tschopp J. Inhibition of death receptor signals by cellular FLIP. Nature. 1997; 388:190-5. https://doi.org/10.1038/40657.

13. Golks A, Brenner D, Fritsch C, Krammer PH, Lavrik IN. c-FLIPR, a new regulator of death receptor-induced apoptosis. J Biol Chem. 2005; 280:14507-13. https://doi. org/10.1074/jbc.M414425200. 
14. Scaffidi C, Schmitz I, Krammer PH, Peter ME. The role of c-FLIP in modulation of CD95-induced apoptosis. J Biol Chem. 1999; 274:1541-8.

15. Wilson TR, Redmond KM, McLaughlin KM, Crawford N, Gately K, O’Byrne K, Le-Clorrenec C, Holohan C, Fennell DA, Johnston PG, Longley DB. Procaspase 8 overexpression in non-small-cell lung cancer promotes apoptosis induced by FLIP silencing. Cell Death Differ. 2009; 16:1352-61. https://doi.org/10.1038/cdd.2009.76.

16. Chen M, Du Y, Qui M, Wang M, Chen K, Huang Z, Jiang M, Xiong F, Chen J, Zhou J, Jiang F, Yin L, Tang $\mathrm{Y}$, et al. Ophiopogonin B-induced autophagy in nonsmall cell lung cancer cells via inhibition of the PI3K/Akt signaling pathway. Oncol Rep. 2013; 29:430-6. https://doi. org/10.3892/or.2012.2131.

17. Kou J, Sun Y, Lin Y, Cheng Z, Zheng W, Yu B, Xu Q. Antiinflammatory activities of aqueous extract from Radix Ophiopogon japonicus and its two constituents. Biol Pharm Bull. 2005; 28:1234-8.

18. Xu QJ, Hou LL, Hu GQ, Xie SQ. [Molecular mechanism of ophiopogonin B induced cellular autophagy of human cervical cancer HeLa cells]. Yao Xue Xue Bao. 2013; 48:855-9.

19. Mizushima N. Autophagy: process and function. Genes Dev. 2007; 21:2861-73. https://doi.org/10.1101/gad.1599207.

20. Baehrecke EH. Autophagy: dual roles in life and death? Nat Rev Mol Cell Biol. 2005; 6:505-10. https://doi.org/10.1038/ nrm1666.

21. Levy JM, Thorburn A. Targeting autophagy during cancer therapy to improve clinical outcomes. Pharmacol Ther. 2011; 131:130-41. https://doi.org/10.1016/j. pharmthera.2011.03.009.

22. Levine B, Kroemer G. Autophagy in the pathogenesis of disease. Cell. 2008; 132:27-42. https://doi.org/10.1016/j. cell.2007.12.018.

23. Weckman A, Rotondo F, Di Ieva A, Syro LV, Butz H, Cusimano MD, Kovacs K. Autophagy in endocrine tumors. Endocr Relat Cancer. 2015; 22: R205-18. https://doi. org/10.1530/erc-15-0042.

24. Kimmelman AC. The dynamic nature of autophagy in cancer. Genes Dev. 2011; 25:1999-2010. https://doi. org/10.1101/gad.17558811.

25. Shi S, Wang Q, Xu J, Jang JH, Padilla MT, Nyunoya T, Xing C, Zhang L, Lin Y. Synergistic anticancer effect of cisplatin and Chal-24 combination through IAP and c-FLIPL degradation, Ripoptosome formation and autophagy-mediated apoptosis. Oncotarget. 2015; 6:164051. https://doi.org/10.18632/oncotarget.2746.

26. MacFarlane M. TRAIL-induced signalling and apoptosis. Toxicol Lett. 2003; 139:89-97.

27. Wang S, El-Deiry WS. TRAIL and apoptosis induction by TNF-family death receptors. Oncogene. 2003; 22:8628-33. https://doi.org/10.1038/sj.onc.1207232.

28. Zobalova R, Stantic M, Prokopova K, Dong LF, Neuzil J. Cancer cells with high expression of CD133 exert FLIP upregulation and resistance to TRAIL-induced apoptosis. Biofactors. 2008; 34:231-5. https://doi.org/10.3233/ bio-2009-1076.

29. Chen M, Guo Y, Zhao R, Wang X, Jiang M, Fu H, Zhang $\mathrm{X}$. Ophiopogonin B induces apoptosis, mitotic catastrophe and autophagy in A549 cells. Int J Oncol. 2016; 49:316-24. https://doi.org/10.3892/ijo.2016.3514.

30. Kroemer G, Marino G, Levine B. Autophagy and the integrated stress response. Mol Cell. 2010; 40:280-93. https://doi.org/10.1016/j.molcel.2010.09.023.

31. Kabeya Y, Mizushima N, Ueno T, Yamamoto A, Kirisako T, Noda T, Kominami E, Ohsumi Y, Yoshimori T. LC3, a mammalian homologue of yeast Apg8p, is localized in autophagosome membranes after processing. Embo j. 2000; 19:5720-8. https://doi.org/10.1093/emboj/19.21.5720.

32. Mukhopadhyay S, Panda PK, Sinha N, Das DN, Bhutia SK. Autophagy and apoptosis: where do they meet? Apoptosis. 2014; 19:555-66. https://doi.org/10.1007/ s10495-014-0967-2.

33. Jin CY, Park C, Hwang HJ, Kim GY, Choi BT, Kim WJ, Choi YH. Naringenin up-regulates the expression of death receptor 5 and enhances TRAIL-induced apoptosis in human lung cancer A549 cells. Mol Nutr Food Res. 2011; 55:300-9. https://doi.org/10.1002/mnfr.201000024.

34. Xu J, Xu X, Shi S, Wang Q, Saxton B, He W, Gou X, Jang JH, Nyunoya T, Wang X, Xing C, Zhang L, Lin Y. Autophagy-Mediated Degradation of IAPs and c-FLIP(L) Potentiates Apoptosis Induced by Combination of TRAIL and Chal-24. J Cell Biochem. 2016; 117:1136-44. https:// doi.org/10.1002/jcb.25397.

35. Nazim UM, Moon JH, Lee JH, Lee YJ, Seol JW, Eo SK, Lee JH, Park SY. Activation of autophagy flux by metformin downregulates cellular FLICE-like inhibitory protein and enhances TRAIL- induced apoptosis. Oncotarget. 2016; 7:23468-81. https://doi.org/10.18632/oncotarget.8048. 